\title{
Perception of sensory impressions in children from music classes and their peers from general classes in Poland - a comparison
}

\author{
DOI: https://doi.org/10.5114/pq.2019.87736
}

\author{
Ewa Gieysztor, Paulina Kurzaj, Anna Maria Choińska, Mateusz Kowal, \\ Anna Pecuch, Wojciech Borowicz, Małgorzata Paprocka-Borowicz \\ Physiotherapy Department, Faculty of Health Sciences, Wroclaw Medical University, Wroclaw, Poland
}

\section{Abstract}

Introduction. School age is a very important and intense period in children's development. The central nervous system has an enormous absorptivity of sensory impressions. In the recent decade, an increased number of diagnoses of sensory disorders has been noticed in children in Poland. Alvin noted that musical compositions provided a good source of support for a child to acquire both auditory and tactile sensory experiences. The main aim of the study was to compare the level of sensory integration in children from music classes and their peers from general classes.

Methods. Two groups of children participated in the study: group M, 14 boys and 11 girls attending second classes in music schools, and group G, 16 boys and 11 girls attending general classes. Both groups were subjected to a clinical trial by Przyrowski and the Southern California Test according to Ayres. In addition, the parents of the examined children were asked to complete the Sensorimotor Child Development Questionnaire.

Results. The process of sensory integration took place correctly in both groups of children. The results suggest that children in music classes are better at bilateral motor coordination, finger identification, and finger-thumb test (average results above the norm). Children in general classes were more able to maintain static balance with closed as well as open eyes than their musical peers.

Conclusions. Music education positively influences the process of sensory integration in children. It can be a good source of a child's brain stimulation.

Key words: sensory integration, music training, children

\section{Introduction}

The nervous system matures with age. A child receives a variety of sensory impressions already in the mother's womb. These are stimuli related to position, movement, and the feeling of gravity. These processes give the beginning of the sensory integration development [1-3].

Sensory integration is a very complex neuronal process that takes place in the nervous system. It is primarily about receiving, processing, and interpreting new incentives recorded by the senses, and also integrating them with those that have already been received. This process is possible thanks to the proper functioning of sensory systems (including the visual, tactile, auditory, and proprioceptive ones). The ability to integrate sensory impulses affects not only simple reflex reactions but also the precision of individual movements, coordination, or balance. It is responsible for overall behaviour and relationships with the surrounding environment. It is the source of information about the world [1, 4, 5].

Music combines many sensory impressions. Listening to music is a complex phenomenon that requires the involvement of the nervous system, cardiovascular and emotional factors, and psychological and behavioural aspects. Nowadays, it is still not possible to accurately state what is happening in the neurons of the brain under its influence. There is no consensus among scientists from different fields. The research by Rauscher and Hong has shown that Mozart's effect is to accelerate physical and chemical processes in nerve cells. On the other hand, Gardner believes that music has a significant impact on the human body, but such properties are not attributed solely to Mozart's compositions. According to Stamper, listening to Mozart's compositions can lead to pioneering neural pathways that are responsible for creating visual images [6, 7].

School age is a very important and intense period in the development of a child. The central nervous system has an enormous absorptivity of sensory impressions. Only a wellfunctioning nervous system allows full use of the resources of the human mind. In the recent decade, an increased number of diagnoses of sensory disorders has been noticed in children in Poland ( 1 child per 20 has a sensory integration disorder diagnosed) [8]. The central nervous system of children in classes I-III shows a great absorption of sensory impressions. The memory of a student aged $7-10$ years is very capacious. Proper sensory stimulation can therefore have a positive influence on the learning process and consequently on the correct development of the child. Alvin noted that musical compositions provided a good source of support for a child to acquire both auditory and tactile sensory experiences. Therefore, they can be a good stimulator for development [8-10].

The main purpose of the research was a comparison of the level of sensory integration in children from second music classes and those from second general classes. Additional aims were the following:

Correspondence address: Ewa Gieysztor, Physiotherapy Department, Faculty of Health Sciences, Wroclaw Medical University, ul. Grunwaldzka 2, 50-355 Wrocław, Poland, e-mail: ewa.gieysztor@umed.wroc.pl

Citation: Gieysztor E, Kurzaj P, Choińska AM, Kowal M, Pecuch A, Borowicz W, Paprocka-Borowicz M. Perception of sensory impressions in children from music classes and their peers from general classes in Poland - a comparison. Physiother Quart. 2019;27(4):26-30; doi: https://doi.org/10.5114/pq.2019.87736. 
- verification if the process of sensory integration goes well in school-aged children;

- assessment of the risk of sensory integration disorders in musical children and their peers in general classes;

- checking whether sex significantly influences the process of sensory integration;

- checking if parents notice symptoms which point at difficulties in processing sensory impressions.

\section{Subjects and methods}

\section{Subjects}

The study involved 52 children aged 7-9 years, divided into 2 groups ( $\mathrm{M}$ - musical classes; $\mathrm{G}$ - general classes). The characteristics of each group are shown in Table 1.

Table 1. Characteristics of the studied groups

\begin{tabular}{|l|c|c|}
\cline { 2 - 3 } \multicolumn{1}{c|}{} & Group M & Group G \\
\hline Population & $\begin{array}{c}25 \text { children } \\
\text { (14 boys, 11 girls) }\end{array}$ & $\begin{array}{c}27 \text { children } \\
\text { (16 boys, 11 girls) }\end{array}$ \\
\hline School/class & $\begin{array}{c}\text { Second music class } \\
\text { from Music School } \\
\text { No. 2 in Wroclaw } \\
\text { and National Music } \\
\text { School in Sieradz }\end{array}$ & $\begin{array}{c}\text { Second class } \\
\text { from Primary School } \\
\text { No. 45 in Wroclaw } \\
\text { and Primary School } \\
\text { in Brzezno }\end{array}$ \\
\hline $\begin{array}{l}\text { Qualifying } \\
\text { condition }\end{array}$ & $\begin{array}{c}\text { Children have been } \\
\text { attending regularly } \\
\text { music lessons } \\
\text { on any musical } \\
\text { instrument for } \\
\text { at least 2 years }\end{array}$ & $\begin{array}{c}\text { Children have not } \\
\text { learnt to play } \\
\text { any musical } \\
\text { instrument }\end{array}$ \\
\hline $\begin{array}{l}\text { Average age } \\
\text { (years) }\end{array}$ & \begin{tabular}{c}
8.4 \\
\hline
\end{tabular} & 8.6 \\
\hline
\end{tabular}

$\mathrm{M}$ - musical classes, $\mathrm{G}$ - general classes

None of the children participating in the study (from group M or group $\mathrm{G}$ ) had diagnosed epilepsy, motion sickness, autism, attention-deficit hyperactivity disorder, or dyslexia. There was no diagnosis of head trauma, dizziness, hearing impairment, or any other illness that would indicate a malfunctioning vestibular system or that would have increased the risk of disturbances in the integration of sensory impressions. The interviews with parents revealed no significant problems in the development of children in their first years of life (the development was normal) or during pregnancy.

\section{Research tools}

\section{Sensorimotor Child Development Questionnaire}

It comprises 90 questions addressed to parents and allows to detect early symptoms associated with individual sensory integration disorders and to determine the risk of a child's development dysfunction resulting from abnormalities in the processing of stimuli from receptors of all sensory systems. The occurrence of a particular disorder is considered probable with at least $50 \%$ of the key responses [11, 12].

\section{Clinical trial by Przyrowski}

The trial consists of 17 movement tasks set. Depending on the child's performance on each task, the appropriate number of points is awarded. Then the results for the whole study are summed up and compared with the scale proposed by the author. Clinical observation is used to assess the risk of disorder in the function being studied. This, however, does not directly indicate sensory integration disorders. The results interpretation becomes necessary to refer to the other components of the diagnosis $[1,12]$.

\section{Southern California Test according to Ayres}

It evaluates the level of sensory integration in children in accordance with age norms. What is more, it also shows the nature of the change, which may indicate the origin of developmental dysfunctions. The test consists of 11 tasks. Normal values range from -1 to 1 . The Southern California Test by Ayres is useful in making the right diagnosis because it improves the accuracy of observation (standardized result) [1].

\section{Statistical analysis}

The obtained results were developed by using computer programs such as Microsoft Excel and Statistica. In order to check the statistical significance of the results, the Ducan test and Mann-Whitney test were applied. The results were considered statistically significant when the alpha coefficient was equal to or less than 0.05 . This level of statistical significance was established for all statistical tests.

\section{Ethical approval}

The research related to human use has complied with all the relevant national regulations and institutional policies, has followed the tenets of the Declaration of Helsinki, and has been approved by the Bioethical Commission at the Wroclaw Medical University (No. KB - 683/2015).

\section{Informed consent}

Informed consent has been obtained from the legal guardians of all individuals included in this study.

\section{Results}

The Sensorimotor Child Development Questionnaire results reported no sensory disorders in the study participants (low percentages of responses indicating deficits: $8 \%$ in group $\mathrm{M}, 18 \%$ in group $\mathrm{G}$ ). The children had a higher risk of

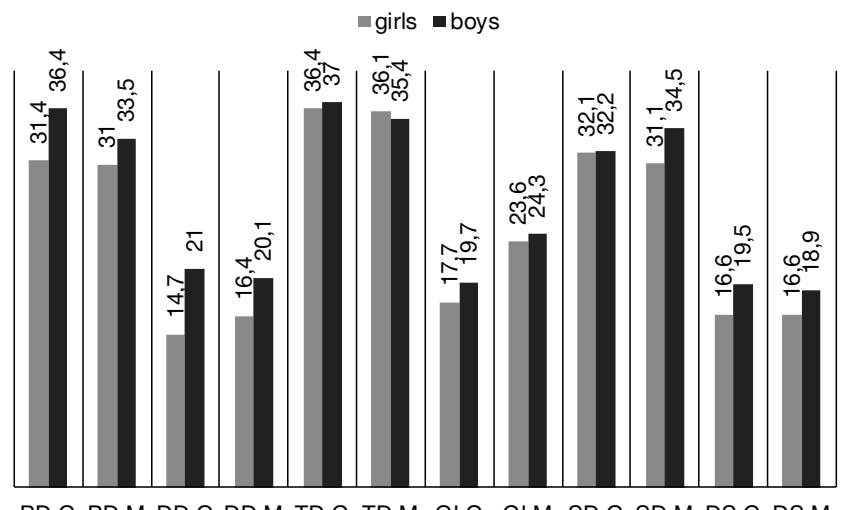

PD G PDM DD G DDM TDG TDM GIG GIM SDG SDM DSG DSM

$\mathrm{G}$ - group $\mathrm{G}, \mathrm{M}$ - group $\mathrm{M}, \mathrm{PD}$ - postural disorder,

DD - developmental dyspraxia, TD - tactile defence,

GI - gravitational insecurity, SD - sensory defence,

DS - disorder of body schema and spatial orientation

Figure 1. Sensorimotor Child Development Questionnaire: average results 
postural and tactile disorders. The lowest risk was observed for developmental dyspraxia and disorders of body schema and orientation in space. Significant differences between the studied groups were found only within gravitational insecurity. Children in music classes had a significantly higher risk of developing such disorders than their peers in general classes. There was also a tendency for girls to be at a lower risk of any sensory integration disorder than boys of the same age. However, statistical significance has not been demonstrated in the sex stratification. It would be worth continuing the observation in a larger population (Figure 1).

As for the gravitational insecurity mentioned above, with a significantly lower risk in general classes compared with the music group, the differences were statistically significant at $p=0.017$. Girls who learned to play musical instruments attained an average of $23.6 \%$ of responses in accordance with the key to the risk of gravity danger. Their male peers obtained a very similar result of $24.3 \%$. In group $\mathrm{G}$, the results of both girls and boys were significantly lower than in group $\mathrm{M}$. Females mostly achieved $17.7 \%$, while males scored slightly higher: $19.7 \%$.

Summing up the results of all clinical observation tests implied a significant risk of disorders in both groups $(52 \%$ of the subjects). In children of general classes, sensory integration disorder was found in $30 \%$ of the subjects. In the music group, the percentage was almost 2 times lower and reached $16 \%$. No serious disturbances were seen in group $M$. The remaining $32 \%$ of group $M$ children and $18 \%$ of group $\mathrm{G}$ children were normal.

We also analysed the results obtained by the children depending on sex. In the group of students playing musical instruments, sensory integration disorder was found in $21 \%$ of boys and only $9 \%$ of girls; $36 \%$ of musical children and $29 \%$ of their general classmates presented normal values. In the music classes, the risk of dysfunction was observed more commonly in girls (55\%) than in boys (50\%). Students playing musical instruments scored mostly 49.2 points, while their female peers received a slightly lower result of 46.8 points. Similar tendencies were noted in group G. Disability of sensory integration was reported in $38 \%$ of boys and almost half less in girls (18\%); $19 \%$ of girls and $18 \%$ boys maintained normal values. As many as $64 \%$ of girls and $44 \%$ of boys who did not play instruments were at risk of developing disorders. The average performance of group $G$ was lower than that in group M. Girls received mostly 47.5 points and their male peers achieved slightly lower results of 46.3 points.

In the finger-thumb test, a child was to touch each finger with the thumb. Firstly, the examiner showed how it should be done correctly. Then the child repeated the movement. In this time, the examiner observed if the participant fulfilled all of the 3 observation conditions: movement fluidity, correct arrangement of palm bends, and bilateral coordination. In the music classes, the vast majority of children (72\%) achieved the correct reaction in the finger-thumb test (3 points); $20 \%$ of the respondents did not fulfil only 1 condition ( 2 points); 2 or more observation conditions were not fulfilled by 2 children, which accounted for $8 \%$ of group M (1 point) (Figure 2 ). In the general classes, only $37 \%$ of the respondents fully dealt with the task ( 3 points). As many as $26 \%$ of the children in group $\mathrm{G}$ did not meet 2 or more conditions (1 point), and $37 \%$ did not meet only 1 condition (2 points) in the fingerthumb test (Figure 3 ). The differences between the 2 groups were statistically significant at $p=0.03$.

For most instances of the Southern California Test according to Ayres, children from both groups were age-matched.

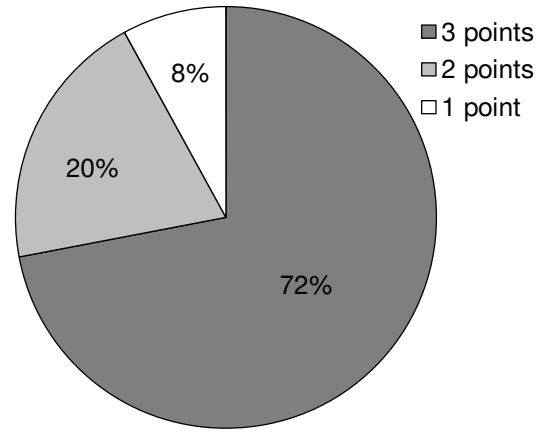

Figure 2. Finger-thumb test results for group $M$

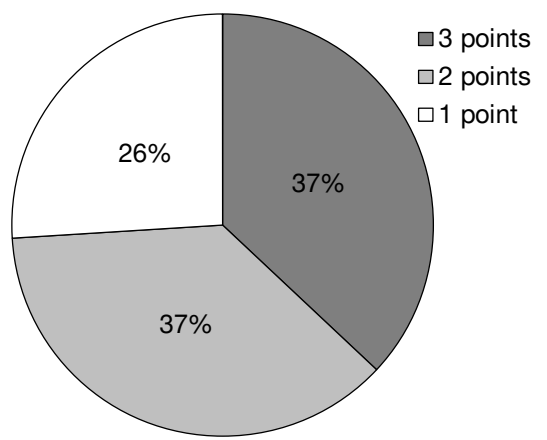

Figure 3. Finger-thumb test results for group $\mathrm{G}$

postrotatory nystagmus in both music and general classes. In group $\mathrm{M}$, the average score was -1.8 among girls and -1.5 in boys (well below normal). Children who did not play musical instruments scored -2 (girls) and -1.9 (boys) (well below normal).

Moreover, it was noted that boys were much worse at graphesthesia. In group M, boys achieved results below their age norm. Boys' average score was -1.1 in group $M$ and -0.7 in group $\mathrm{G}$. Girls obtained -0.4 and 0 , respectively.

Girls, in both music and general classes, were above average in the pattern copying attempt. Also, children in group $M$ achieved an average score higher (1.8 for girls and 1.7 for boys) than those in group $\mathrm{G}$ ( 1.3 for both boys and girls).

It was also observed that students playing musical instruments dealt far better with the location of the touch stimulus. In group M, the test result was 1.2 for girls (above age standard) and 0.9 for boys. In group $\mathrm{G}$, both boys and girls reached the age norm and their average score was 0.4 .

\section{Discussion}

Many scientists, among others, Wiśniewska and Przyrowski, have noticed that the development and sensory integration of children in both school and pre-school age is a growing problem. Currently, it is estimated that $12-30 \%$ of the paediatric population in Poland may show deficits in the integration of sensory impressions. Moreover, Przyrowski has determined the risk range of such disorders as $40-80 \%$ $[1,9,11,12]$. The analysis of own results leads to similar conclusions. The study reported a $52 \%$ risk of sensory integration disorders in both music and general classes students. On the other hand, on the basis of clinical observation, 30\% of group $\mathrm{G}$ and $16 \%$ of group $M$ were diagnosed with this disorder. For deeper analysis of the problem, research should be continued in a larger population. Attention should be paid to the diagnosis and observation of children and to educating parents and teachers about the opportunities for supporting the proper development of the child in order to avoid school difficulties. 
The process of shaping the ability to properly integrate sensory impressions takes place in several stages. According to Ayres, the central nervous system of a 7-year-old should already deal relatively well with the registration and sensory organization $[12,13]$. The presented study shows that the process of sensory integration was going well among both music and general classes 7-9-year-olds.

Researchers dealing with the issue of integrating sensory stimuli have noted an association of the prevalence of this process disorder with sex. Fisher, Watson, Short, as well as Ottenbacher show that boys are more likely to report deficits in recording and processing sensory impressions [14, 15]. Our own results prompt similar conclusions. Sensory integration deficits turned out more common in boys than in girls. The disorder was detected in $21 \%$ of students playing musical instruments and in $38 \%$ of the general classes by using the clinical observation tool by Przyrowski. Among girls, deficits in sensory integration were found only in $9 \%$ of group $M$ students and in $18 \%$ of group G. Moreover, there was a tendency among girls in both groups to achieve higher kinaesthesia scores, as well as to be more able than boys to maintain balance with both closed and open eyes.

Brockett et al. [16] used the concept of hearing integration training in their work. They indicate that it can become an effective element of sensory integration therapy. Musical training is beneficial for the development of both mental and motor skills.

Music exerts a positive effect on the maturity of sensory integration processes. However, there are few reports on psychomotor development of musically gifted children. In the present research, we observed the presence of statistically significant differences between the general classes group and the learners playing musical instruments. Playing instruments can affect bilateral motor coordination, finger identification, and fingerprint test results. For the aforementioned tests, the majority of the respondents were rated in accordance with age. However, in group $\mathrm{M}$, the values were above normal, suggesting that these children are better at handling touch and vestibular information and may be more able to concentrate on the task. They show a higher ability to perform precise movements as well as to plan hand motion. Regular music training makes children better equipped to integrate stimuli from both sides of the body (high level of hemispheric specialization).

De Quiros [17] found that dysfunction in the processing of vestibular information was a cause of children's difficulties in learning. In our own study, it was noted that both groups had some difficulty in tests that required efficient integration of vestibular stimuli. As many as $84 \%$ of group $M$ respondents and $96 \%$ of those in group $\mathrm{G}$ scored well below the standard in the postrotatory nystagmus test. A significant reduction in the duration of ocular movement after rotation was observed, which may indicate difficulties in integrating and sensory processing of the vestibular system into hyposensitivity. However, we should look closely at the postrotatory nystagmus test and be careful in interpreting its results. It constitutes an auxiliary indicator, which should be considered as a whole, in relation to the remaining tests. The causes of the depressed nystagmus may be many. Zając et al. [18] confirmed that vestibular function and postural control in children could be affected even by a thyroid disease. Kranowitz [19] proved that problems occurring in early school children had a significant relationship with both intra- and intermodal disorders of not only vestibular, but also at proprioceptive and tactile systems.
There are a number of tests, performed with both open and closed eyes, to investigate the ability of balance in children. Maintaining a stable posture requires this skill acquisition. Various authors of many studies have pointed to the deterioration of the body stability in the context of excluding visual stimuli. Wilczyński and Zawada [20] stated that children did not use their eyes to maintain balance. He noticed that the equilibrium parameters with closed eyes did not deteriorate. This may be due to the lack of adequately developed sensory integration capabilities (especially in the processing of vestibular and visual experiences). This process is still developing in children [21]. Our study also revealed that 7-8-year-olds had quite a hard time balancing their bodies. Children in the general classes were more able to maintain static balance both with their eyes closed and opened. In the music classes, $12 \%$ of the subjects had difficulty balancing on one leg with closed eyes. The observed differences were statistically significant. Moreover, girls (in both groups) turned out better at this test than their male peers. The differences can be attributed to the fact that children who undergo instrumental training spend a lot of time in static conditions, thereby limiting their motor activity. This does not have a positive effect on the development of balance abilities. Some other authors suggest different motor abilities due to exercises and school achievements in the case of motor stimuli assessed in different ways [22-25]. It is recommended to introduce more hours of physical education for children in music classes. There was also a tendency for group $\mathrm{G}$ children not to achieve higher results in the trial of eye movements and graphesthesia than their musical mates. This may prove to be better in terms of visual perception and visualization of the touch stimulus. It can affect the ability to read and write. However, these differences were not statistically significant (on the materiality boundary). It is advisable to further observe the children in this regard.

\section{Conclusions}

- Music education positively influences the process of sensory integration in children. Music lessons in schools can be a good source of stimulation for a child's brain.

- It is recommended to introduce more hours of physical activity for children playing instruments to improve their balance.

- One should look closely at the postrotatory nystagmus test and be careful in interpreting its results. It constitutes an auxiliary indicator, which should be considered as a whole, in relation to the remaining tests.

- Both in the music and general classes, there is a risk of sensory integration disorder in every other child. Attention should be paid to the diagnosis and observation of children and to educating parents and teachers about the opportunities for supporting the proper development of the child in order to avoid school difficulties.

- Further studies should be conducted in a larger population. They will allow to more closely track the dependence of music education and the process of sensory integration in children.

\section{Disclosure statement}

No author has any financial interest or received any financial benefit from this research.

\section{Conflict of interest}

The authors state no conflict of interest. 


\section{References}

1. Przyrowski Z. Sensory integration. Introduction to the theory, diagnosis, and therapy [in Polish]. Warszawa: Empis; 2013.

2. Pyda-Dulewicz A, Pepaś R, Konopka W. Sensory integration therapy in the rehabilitation of balance disorders in children [in Polish]. Otolaryngologia. 2014;13(4): 186-190.

3. Radziyewska M, Dziągwa E, Radziyewsky P. Sensory integration disorders in children and teenagers [in Polish]. Pedagogika, Psihologia. 2012;4:135-140.

4. Dekker TM, Ban H, van der Velde B, Sereno MI, Welchman AE, Nardini M. Late development of cue integration is linked to sensory fusion in cortex. Curr Biol. 2015; 25(21):2856-2861; doi: 10.1016/j.cub.2015.09.043.

5. Mückschel M, Stock AK, Dippel G, Chmielewski W, Beste C. Interacting sources of interference during sensorimotor integration processes. Neuroimage. 2016; 125:342-349; doi: 10.1016/j.neuroimage.2015.09.075.

6. Dawson WJ. Benefits of music training are widespread and lifelong: a bibliographic review of their non-musical effects. Med Probl Perform Art. 2014;29(2):57-63; doi: 10.21091/mppa.2014.2014.

7. Penhune VB. Sensitive periods in human development: evidence from musical training. Cortex. 2011;47(9): 1126-1137; doi: 10.1016/j.cortex.2011.05.010.

8. Odżygóźdź M, Cylkowska-Nowak M. The influence of rehabilitation with sensory integration method on the development of children with sensorimotor disorders [in Polish]. In: Majchrzycki M, Gajewska E, ŁańczakTrzaskowska M (eds.), Dysfunctions of the locomotor system. Interdisciplinary understanding of problems related to child diagnostics and therapy [in Polish]. Poznań: Uniwersytet Medyczny; 2012; 70-86.

9. Stańczyk M. Integration sensory disorders and learning difficulties [in Polish]. Życie Szkoły. 2014;3:10-13.

10. Choińska AM, Sadowska L, Filipowski H, Bibrowska R, Polczyk A. The occurrence of the risk of sensory integration disorders in children aged 3-8 years [in Polish]. In: Patkiewicz J (ed.), The social potential of disabled children and adolescents [in Polish]. Wrocław: TWK; 2011; 25-39.

11. Przyrowski Z. Clinical observation [in Polish]. Warszawa: Empis; 2013.

12. Ayres AJ. Sensory integration and the child. Los Angeles: Western Psychological Services; 1991.

13. Danielak J, Choińska AM, Gieysztor E, Sadowska L. Sensory integration disorders in early school-age children in the music and general class [in Polish]. In: Patkiewicz $\mathrm{J}$ (ed.), Every disabled child will be an adult and a senior [in Polish]. Wrocław: TWK; 2015; 57-70.

14. Royeen CB, Lane SJ. Tactile processing and sensory defensiveness. In: Fisher AG, Murray EA, Bundy AC (eds.), Sensory integration. Theory and practice. Philadelphia: F.A. Davis Company; 1991; 108-133.

15. Fisher AG, Murray EA, Bundy AC. Sensory integration. Theory and practice. Philadelphia: F.A. Davis Company; 1991.

16. Brockett SS, Lawton-Shirley NK, Kimball JG. Berard auditory integration training: behavior changes related to sensory modulation. Autism Insights. 2014;6:1-10; doi: 10.4137/AUI.S13574.

17. De Quiros JB. Diagnosis of vestibular disorders in the learning disabled. J Learn Disabil. 1976;9(1):39-47; doi: $10.1177 / 002221947600900108$.
18. Zając M, Orendorz-Frączkowska K, Kubacka M, Żak T, Noczyńska A. Vestibular organ and postural control in children with autoimmune thyroid diseases [in Polish]. Otolaryngologia. 2015;14(4):222-227.

19. Kranowitz CS. The out-of-sync child. Recognizing and coping with sensory integration dysfunction. New York: The Berkley Publishing Group; 1998.

20. Wilczyński J, Zawada K. The impact of sensory integration therapy on gross motor function in children after prenatal exposure to alcohol. Stud Med. 2015;31(1):10-17; doi: $10.5114 / \mathrm{ms} .2015 .49947$.

21. Walicka-Cypryś K, Skalska-Izdebska R, Drzał-Grabiec J, Sołek A. The relationship between posture and postural stability in early school-aged children [in Polish]. Post Rehab. 2013;4:47-54.

22. Dickinson BD, Duncan MJ, Eyre ELJ. Exercise and academic achievement in children: effects of acute classbased circuit training. Hum Mov. 2016;17(1):4-7; doi: 10.1515/humo-2016-0007.

23. Das Virgens Chagas D, Batista LA. Interrelationships among motor coordination, body fat percentage, and physical activity in adolescent girls. Hum Mov. 2015; 16(1):4-8; doi: 10.1515/humo-2015-0019.

24. Czajka K, Sławińska T, Kołodziej M, Kochan K. Assessment of physical activity by pedometer in Polish preschool children. Hum Mov. 2015;16(1):15-19; doi: 10.1515/humo-2015-0021.

25. Gieysztor EZ, Choińska AM, Paprocka-Borowicz M. Persistence of primitive reflexes and associated motor problems in healthy preschool children. Arch Med Sci. 2018;14(1):167-173; doi: 10.5114/aoms.2016.60503. 